\title{
Antiestrógenos: mecanismo de acción y aplicaciones clínicas
}

\author{
Arturo Barrón-González, M en $C_{,}{ }^{(1)}$ Joel Arias-Martínez, M en $C_{,}{ }^{(1)}$ \\ Ivone Castro-Romero, Dra en C. ${ }^{(1)}$
}

\begin{abstract}
Barrón-González A,Arias-Martínez J, Castro-Romero I.

Antiestrógenos: mecanismo de acción y aplicaciones clínicas.

Salud Publica Mex 2001;43:577-584.

El texto completo en inglés de este artículo está disponible en: http://www.insp.mx/salud/index.html
\end{abstract}

\section{Resumen}

Los antiestrógenos son compuestos que antagonizan la acción de los estrógenos compitiendo por su receptor. Los estrógenos están implicados en la proliferación y diferenciación de las células blanco y se consideran entre los principales factores de riesgo para el desarrollo de cáncer de mama y útero. Algunos antiestrógenos, entre ellos el Tamoxifén, son utilizados como terapia coadyuvante en el tratamiento del cáncer de mama y se ha propuesto su inclusión en los programas de prevención, en mujeres con alto riesgo. Los antiestró genos se clasifican en tipo I o parciales (agonista/antagonista), y tipo II o puros (antagonista puro), los cuales tienen mecanismos de acción diferentes. Debido al continuo avance en el desarrollo de nuevos compuestos con actividad antiestrogénica, y su importancia aplicativa en clínica. En este documento se presenta una revisión del estado actual del conocimiento de estos compuestos, su mecanismo de acción y su aplicación clínica. El texto completo en inglés de este artículo está disponible en: http:// www.insp.mx/salud/index.html

Palabras clave: antagonistas del estrógeno; estrógenos moduladores selectivos del receptor de estrógenos, neo plasmas de la mama

\author{
Barrón-González A,Arias-Martínez J, \\ Castro-Romero I. \\ Antiestrogens: Mechanism of action \\ and clinical applications. \\ Salud Publica Mex 2001;43:577-584. \\ The English version of this paper \\ is available at: http://www.insp.mx/salud/index.html
}

\section{A bstract}

Antiestrogens are compounds that inhibit estrogen action by competing for its receptors. Estrogens are involved in the proliferation and differentiation of target cells and are among the main risk factors for breast and uterine cancer. Some antiestrogens, such asTamoxifen, are used as adjuvant therapy against breast cancer, and have been proposed to be included in prevention programs for women at high risk of cancer. Antiestrogens are classified according to their action mechanisms into Type I or partial (agonistic/antagonistic), andType II or pure (pure antagonistic).Advancements in the development of new antiestrogens and their clinical importance are reviewed in this paper, as well as their mechanism of action and clinical applications. The English version of this paper is available at: http://www.insp.mx/salud/ index.html

Key words: estrogen antagonists; estrogens, selective estrogen receptor modulators; breast neoplasms

(1) Departamento de Bioquímica y Biología Molecular. Instituto $\mathrm{N}$ acional de Perinatología. Secretaría de Salud, México, D .F., México.

Fecha de recibido: 19 de octubre de 2000 - Fecha de aprobado: 23 de mayo de 2001

Solicitud de sobretiros: D ra. Ivone C astro Romero, D epartamento de Bioquímica y Biología Molecular, Instituto $\mathrm{N}$ acional de Perinatología.

Montes U rales 800, colonia Lomas de Virreyes, 11000, México, D.F., México.

Correo electrónico: jcastror@ mailer.main.conacyt.mx 
$A$ pesar de que hasta ahora no existe un esquema claro del mecanismo de acción de los estrógenos, en los últimos años ha sido posible desarrollar estrategias de tratamiento de algunas patologías, como el cáncer de mama, altamente relacionadas con la acción de estos esteroides. ${ }^{1-2}$ En este caso particular, los esfuerzos se han enfocado en la búsqueda de nuevos compuestos con capacidad inhibitoria de la proliferación de las células malignas, que coadyuven, por un lado, al control de la enfermedad, y por otro, que sean selectivos; es decir, que ejerzan un efecto antagonista en el tejido canceroso y agonista en aquellos tejidos estrógeno-dependientes, como es el caso del tejido óseo. ${ }^{3-5}$ Puesto que algunos de estos compuestos son de uso actual en la clínica ó se encuentran en etapa de investigación, consideramos importante revisar los avances en el conocimiento en este campo. En el presente trabajo se hace una breve revisión de su estructura química y su mecanismo de acción, así como de las aplicaciones clínicas actuales.

Los estrógenos son hormonas esteroides que ejercen múltiples efectos, principalmente sobre la proliferación y diferenciación celular en diversos órganos, como hipotálamo, ${ }^{6}$ hipófisis, ${ }^{7}$ útero, ${ }^{8}$ mama,${ }^{9}$ ovario, ${ }^{10}$ hueso e hígado. ${ }^{11-12} \mathrm{Su}$ acción en el ámbito celular se ejerce a través de un receptor nuclear específico, conocido como receptor de estrógenos (RE), el cual también es utilizado por los antiestrógenos, bloqueando de esta manera la expresión de genes, acción que depende del estímulo estrogénico. Puesto que para entender el mecanismo mediante el cual actúan los antiestrógenos, es necesario conocer primero cómo actúan los estrógenos. ${ }^{13}$ En la primera parte de este documento abordaremos las características principales del receptor específico para este esteroide, así como su función.

El receptor de estrógenos humano (REa) fue clonado y secuenciado a partir de un carcinoma de mama humano (MCF 7) ${ }^{14}$ y se identificó su forma $\beta, 10$ años después, a partir de una genoteca de expresión de testículo humano, ${ }^{15}$ conociéndose hasta ahora otras variantes. ${ }^{16-18}$ Las formas $\alpha$ y $\beta$ presentan en total $45 \%$ de homología y contienen la misma regionalización funcional, pero sólo presentan 96\% de homología en el dominio de unión al DNA, (DBD), y 56\% en el dominio de unión a la hormona (HBD) ${ }^{19}$ (figura 1).

El gen del REa humano se localiza en el cromosoma $6 \mathrm{q} 25.1{ }^{20} \mathrm{y}$ el de la forma $\beta$ en el cromosoma 14q22-24. ${ }^{16}$ El primero codifica para una proteína de $65 \mathrm{kDa}$, formada por 595 aminoácidos (aa), se localiza principalmente en mama, útero, hipotálamo, hipófisis y ovario. El segundo codifica para dos isoformas, una de $55 \mathrm{kDa}$ (485 aa) y otra de $60 \mathrm{kDa}(530 \mathrm{aa}),{ }_{,}{ }^{21}$ las cuales se expresan principalmente en riñón, timo, pulmón, bazo, hipotálamo, hipófisis, próstata, testículo, ovario, sistema digestivo, vejiga y glándula mamaria. ${ }^{16}$ Las formas $\alpha$ y $\beta$ pueden coexistir en el mismo tejido y en las mismas células y se encuentran formando heterodímeros funcionales entre ellos. ${ }^{22-23}$

La estructura funcional del RE es la que le permite actuar como un transductor de la señal hormonal, ya que ésta contiene varias regiones específicas importantes como el dominio de activación transcripcional 1 (TAF-1), el dominio de unión a DNA (DBD), el dominio de activación transcripcional 2 (TAF-2), y el dominio de unión a la hormona (HBD). Esta estructura funcional es la que le permite al RE unirse a la hormona y sufrir un cambio en su conformación espacial que posibilita la formación de homodímeros (REa-REa o REb-REb) o heterodímeros (REa-REb). Es de esta manera como el complejo hormona-receptor se une directamente a las secuencias consenso en el DNA, conocidas como elementos de respuesta a estrógenos (ERE); y en forma indirecta se une con otros factores de transcripción a los sitios AP-1.24-26 (figura 2).

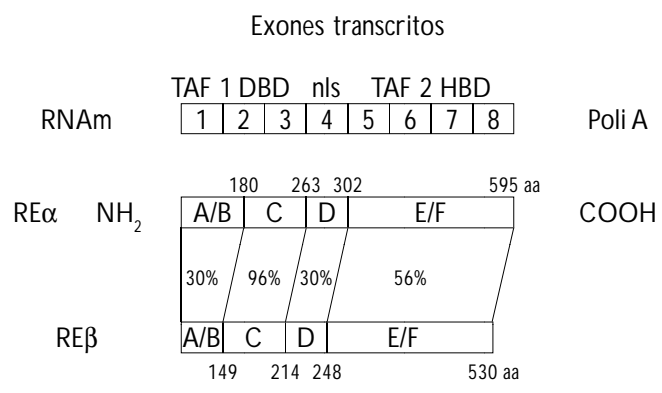

Figura 1. Estructura del receptor de estrógenos. LOS NÚMEROS INTERIORES DEL RNAM CORRESPONDEN A LOS EXONES Y LAS LETRAS EXTERIORES A LAS REGIONES FUNCIONALES. EN LA PROTEÍNA, LAS LETRAS INTERIORES SEÑALAN LAS DIFERENTES REGIONES DEL RECEPTOR Y LOS NÚMEROS EXTERIORES CORRESPONDEN AL NÚMERO DE AMINOÁCIDOS (AA). LOS PORCENTAJES REPRESENTAN EL GRADO DE HOMOLOGÍA ENTRE LOS DOMINIOS DE LAS DOS ISOFORMAS DE RE (MODIFICADO POR OGAWA, 1998).TAF 1 Y 2TAF 2: DOMINIO DE ACTIVACIÓN TRANSCRIPCIONAL. DBD: DOMINIO DE UNIÓN AL DNA. NLS: SEÑAL DE LOCALIZACIÓN NUCLEAR. HBD: DOMINIO DE UNIÓN A LA HORMONA 


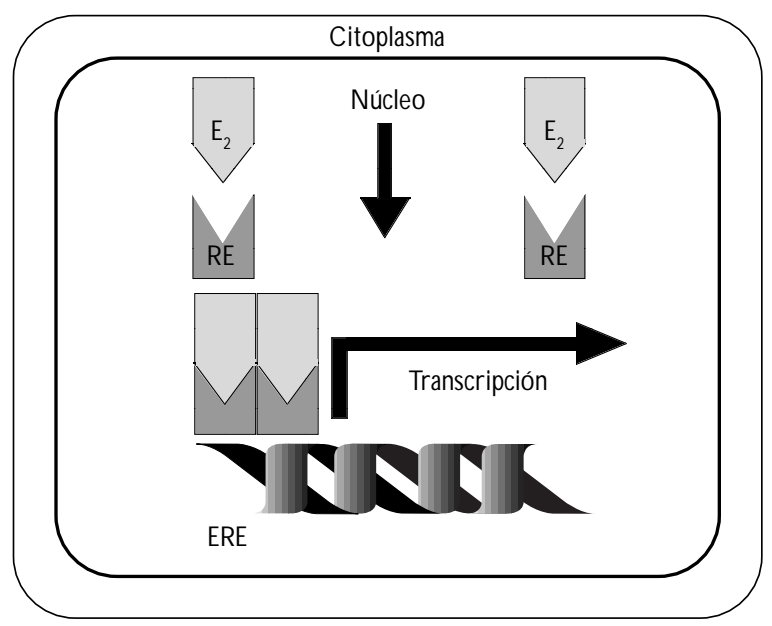

Figura 2. Modelo del mecanismo de acción del ESTRADIOL. $E_{2}$ : ESTRADIOL. RE: RECEPTOR DE ESTRÓGENOS. ERE: ELEMENTO DE RESPUESTA A ESTRÓGENOS

\section{Antiestrógenos}

Tipo I o moduladores selectivos del RE

Estructura química y características principales. Estos compuestos son de naturaleza no-esteroidal, en su mayoría análogos del Tamoxifén y/o de sus metabolitos, siendo la forma 4-hidroxi-tamoxifén, el antiestrógeno más potente ${ }^{27}$ (figura 3). Presentan propiedades agonistas y antagonistas y se denominan moduladores Selectivos del Receptor de Estrógenos (MSRE), debido a que pueden actuar de manera diferente dependiendo del órgano blanco. Estas características han generado interesantes expectativas para su uso potencial en la clínica y actualmente algunas investigaciones hechas en este campo han tenido como objetivo encontrar el MSRE ideal; es decir, que el fármaco conserve su actividad antagonista en tejidos como la mama y el útero, pero que mantenga su efecto estrogénico en hueso, hígado y sistema nervioso central.

Mecanismo de acción. Todos estos fármacos comparten un mecanismo de acción común a través del RE. Su acción se inicia con la unión de estos compuestos al $\mathrm{RE}$, lo cual permite la dimerización del receptor, así como la unión del complejo hormona- receptor al ERE presente en algunos genes. El efecto antiestrogénico se lleva a cabo a través de la inhibición de la actividad del factor de transcripción TAF-2, pero no del TAF-1, el cual se mantiene activo ${ }^{28-30}$ (figura 3). Este mecanismo es, en principio, la razón de su actividad como agonista/antagonista; sin embargo, recientemente se describió un tercer sitio de activación llamado AF2a, el cual puede funcionar cuando AF1 y AF2 están inactivos. ${ }^{31}$ Además de esto, y para hacer más complejo este mecanismo, hay evidencias que sugieren que los antiestrógenos se unen de manera diferente a los TAF, dependiendo de la concentración del fármaco, siendo TAF-2 el de mayor afinidad. Un ejemplo de ello es el efecto antiestrogénico parcial del Tamoxifén, cuya acción a bajas concentraciones se lleva a cabo a través del bloqueo de TAF-2, en tanto que a concentraciones altas inhibe totalmente la acción del RE, bloqueando tanto TAF-1 como TAF-2. ${ }^{32}$
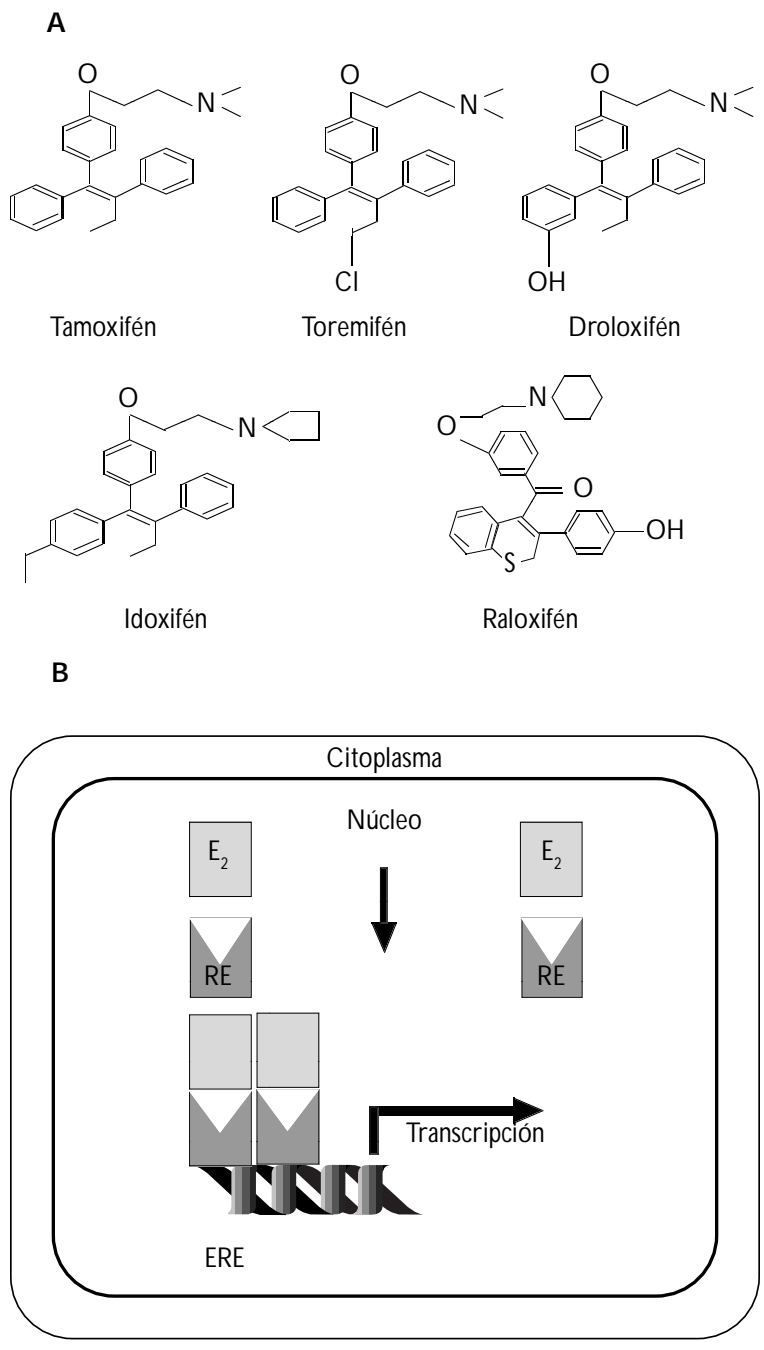

Figura 3. Estructura química (A) y mecanismo de ACCIÓN DE LOS ANTIESTRÓGENOS TIPO I (B). RE: RECEPTOR DE ESTRÓgenOS. ERE: ELEMENTO DE RESPUESTA A ESTRÓGENOS. AE: ANTIESTRÓGENOS 
Este mecanismo sólo explica parcialmente estos efectos, sin embargo no debemos olvidar que los MSRE presentan actividad diferencial entre tejidos, aun cuando las concentraciones del compuesto sean iguales. Es posible que esta especificidad propia del tejido se deba a la presencia tejido-específica de activadores y / o represores involucrados en acción del RE. Estos podrían, eventualmente, determinar la dirección de la respuesta a la estimulación del RE con los diferentes ligandos. Tal es el caso de los co-reguladores que pueden determinar la dirección de la transcripción iniciada por el RE ocupado por MSRE, ${ }^{33}$ de los co-activadores que sólo se unen al RE cuando se encuentra unido a un agonista ${ }^{34} y$ de los correguladores selectivos que potencian el antagonismo de los antiestrógenos e inhiben la activación transcripcional inducida por estrógenos ${ }^{35}$ Algunas evidencias experimentales muestran que la acción del estradiol y los MSRE varía dependiendo de si se unen a la forma $\alpha$ o $\beta$ del RE, y también del tipo de secuencia nucleotídica de los elementos de respuesta. Por ejemplo, Barkem demostró que los MSRE ejercen efectos agonistas sobre los ERE a través del REa, pero no con la forma $\beta{ }^{36}$ y que tanto estos moduladores como el estradiol $\left(\mathrm{E}_{2}\right)$, actúan como activadores transcripcionales a través de los sitios AP-1, a través de la forma $\alpha$, pero no con la forma $\beta .^{37} \mathrm{~A}$ pesar de estos notables avances es evidente que aún no se cuenta con un modelo que explique plenamente el mecanismo o mecanismos de acción de estos compuestos, pero es claro que los factores involucrados en la respuesta, tanto a $\mathrm{E}_{2}$ como a MSRE, son diversos y que este fenómeno es mucho más complejo de lo que se pensaba antes del descubrimiento de la forma $\beta$ del RE.

\section{A plicaciones clínicas}

I) Tamoxifén. Fue aprobado por la Administración para los Alimentos y las Drogas de los Estados Unidos (FDA, por sus siglas en inglés) en 1985, para su uso como adyuvante a la quimioterapia en pacientes posmenopáusicas, con nódulos linfáticos positivos. Desde 1989 su uso se extendió en el tratamiento de pacientes pre y posmenopáusicas con cáncer mamario avanzado, cuyos tejidos tumorales expresaran el RE (RE+) y presencia de múltiples nódulos linfáticos aumentados de tamaño. ${ }^{38}$ Su eficacia clínica para el tratamiento de este tipo de cáncer ha sido ampliamente estudiada y se ha demostrado que incrementa la sobrevida de las mujeres que lo padecen. ${ }^{39}$ En un estudio de evaluación tecnológica, basada en evidencia clínica, ${ }^{40}$ analizando 11 ensayos clínicos que incluían a 15000 pacientes, ${ }^{41}$ se confirmó que el citrato de Tamoxifén (Nolvadex®, Zeneca) es eficaz como terapia adyuvante en mujeres con cáncer de mama RE+, y que la incidencia de tumores de mama contralaterales en estas pacientes se redujo en aproximadamente $36 \%$ cuando recibieron tratamiento con este fármaco. Asimismo, se recomienda su uso en mujeres sometidas a cirugía y radioterapia como tratamiento del carcinoma ductal in situ.

Con relación al cáncer de endometrio está demostrado que, dependiendo del tiempo de uso de este fármaco, se duplica o cuadruplica el riesgo de desarrollarlo, lo cual está asociado con un incremento en la mortalidad de 1-2 / 1000) en mujeres posmenopáusicas que aún conservan útero. Aun cuando se sabe que este incremento en riesgo representa la mitad de la reducción de la incidencia de cáncer de mama contralateral, y que el cáncer de endometrio es menos letal, la decisión del tratamiento con Tamoxifén debe hacerse sobre una evaluación del riesgo-beneficio para la paciente.

II) Toremifén. También conocido como clorotamoxifen (Fareston ${ }^{\circledR}$ ) es un fármaco que tiene actividad antiestrogénica y antitumoral, ${ }^{42}$ y se usa en el tratamiento de pacientes de cáncer de mama avanzado (estadio IV) y con RE+. ${ }^{38}$ Presenta un tercio de la potencia del Tamoxifén, por lo que la dosis recomendada es tres veces mayor que la recomendada para éste. El Toremifén tiene un menor efecto sobre la formación de aductos de DNA en hígado ${ }^{43}$ y por lo tanto un menor efecto carcinogénico en este órgano; ${ }^{44}$ sin embargo el efecto uterotrófico es similar al del Tamoxifen ${ }^{45}$

III) Idoxifén. Es un compuesto 4-iodopirrolidino derivado del Tamoxifén, metabólicamente estable, no presenta efectos tóxicos en hígado ${ }^{46}$ y tiene actividad antiestrogénica y antitumoral en modelos de cáncer de mama, inducidos por nitrosometilurea (NMU) en ratas de laboratorio. ${ }^{47}$ Este fármaco fue desarrollado en los laboratorios SmithKline-Beecham para su eventual utilización en pacientes con resistencia al tratamiento con Tamoxifén.

IV) Droloxifén. El Droloxifén o 3-OH-tamoxifén funciona como un agente antitumoral en animales de laboratorio, ${ }^{48}$ y en algunas pruebas clínicas con mujeres posmenopáusicas con cáncer de mama avanzado se encontró que las tasas de respuesta a este compuesto fluctúan entre 30 y 50\%. Dicha respuesta se obtiene a los 60 días de iniciado el tratamiento, que es bien tolerado por la paciente, aunque se pueden presentar fatiga y náusea. ${ }^{49}$ Este 
fármaco fue desarrollado por los laboratorios Pfizer para el tratamiento de la osteoporosis en mujeres posmenopáusicas. ${ }^{50}$

V) Raloxifén. El Raloxifén (LY 156 758, Keoxifén o Evista $\left.{ }^{\circledR}\right)$ fue desarrollado por los laboratorios Lilly. Es un compuesto que se une al RE con alta afinidad, tiene una potente actividad antiestrogénica y mínimo efecto uterotrófico, ${ }^{51-53} \mathrm{e}$ incluso bloquea la actividad uterotrófica del $\mathrm{E}_{2}$ y del Tamoxifén. ${ }^{54}$ Diferentes estudios han demostrado que este compuesto conserva la densidad mineral ósea después de la ovariectomía en ratas, ${ }^{55-57}$ disminuye los niveles circulantes de colesterol en rata $5^{58}$ y humanos, ${ }^{59}$ tiene actividad antitumoral in vitro $0^{60} \mathrm{y}$ previene la carcinogénesis mamaria en ratas. ${ }^{61-62}$ Estas características lo hacen potencialmente prometedor en pacientes menopáusicas para contrarrestarles la osteoporosis, la hipercolesteroemia o síntomas característicos de esta etapa de la vida. ${ }^{63}$ Existen muy pocos informes sobre el uso de Raloxifén en el tratamiento del cáncer de mama, y los resultados no son alentadores, pues se ha demostrado que este compuesto no tiene efecto sobre los tumores resistentes a Tamoxifén, ${ }^{64}$ ni en aquellos donde no se encuentra expresado el receptor. ${ }^{50}$

\section{Tipo II o puros}

Estructura química y características principales. Son compuestos de naturaleza esteroidal, cuya estructura química se puede ver en la figura 4 . Inhiben la acción de los estrógenos en todas las condiciones en las que han sido probados, y originalmente se utilizaron para el tratamiento de cáncer avanzado, resistente a la terapia con Tamoxifén. ${ }^{50}$

Mecanismo de acción. Estos compuestos tienen una alta afinidad por el RE e inhiben la acción de los estrógenos por competencia por este receptor. Su acción antiestrogénica se efectúa al impedir la dimerización de este receptor, ${ }^{65}$ lo cual no le permite su unión al ERE, y por lo tanto a la transcripción de los genes. Asimismo se ha demostrado que estos compuestos pueden bloquear la translocación del RE al núcleo, lo cual incrementa su degradación citoplasmática. ${ }^{66,67}$ Este modelo de acción explica por qué estos agentes presentan siempre actividad antagonista y bloquean cualquier efecto estrogénico mediado por el RE (figura 4).

Aplicaciones clínicas. De este grupo, el ICI 182780 (Faslodex®) es el único de los antiestrógenos puros que ha sido probado en la clínica. Es un potente antagonista que inhibe el crecimiento de tumores mamarios estimulados por Tamoxifén, ${ }^{68,69}$ inhibe el crecimiento de tumores endometriales ${ }^{70}$ y no ejerce efectos agonistas en el útero de los monos. ${ }^{71}$ Varios estudios clínicos han demostrado que este compuesto no tiene prácticamente efecto estrogénico, pero reduce los niveles de expresión del receptor de progesterona (RPg) y del RE en tumores de mama. ${ }^{72}$ No se ha informado de genotoxicidad o efectos carcinogénicos, ${ }^{73}$ sin embargo se ha demostrado que selecciona células tumorales resistentes a Tamoxifen. ${ }^{74}$ Hasta la fecha no se sabe cómo es metabolizado por el organismo; pero está comprobado que una inyección de $18 \mathrm{mg}$ /día mantiene niveles sanguíneos de $25 \mathrm{ng} / \mathrm{ml}$ una semana después de iniciado el tratamiento, con lo que ocurre un des-

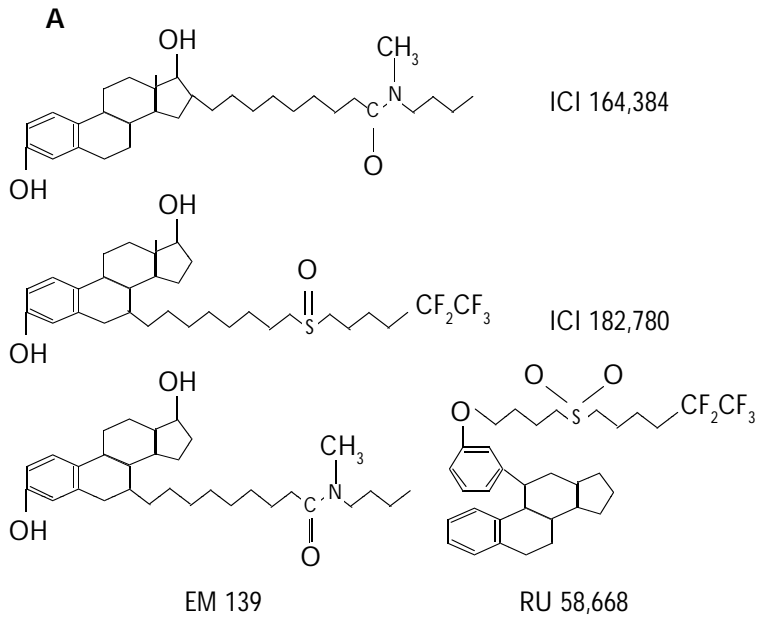

B

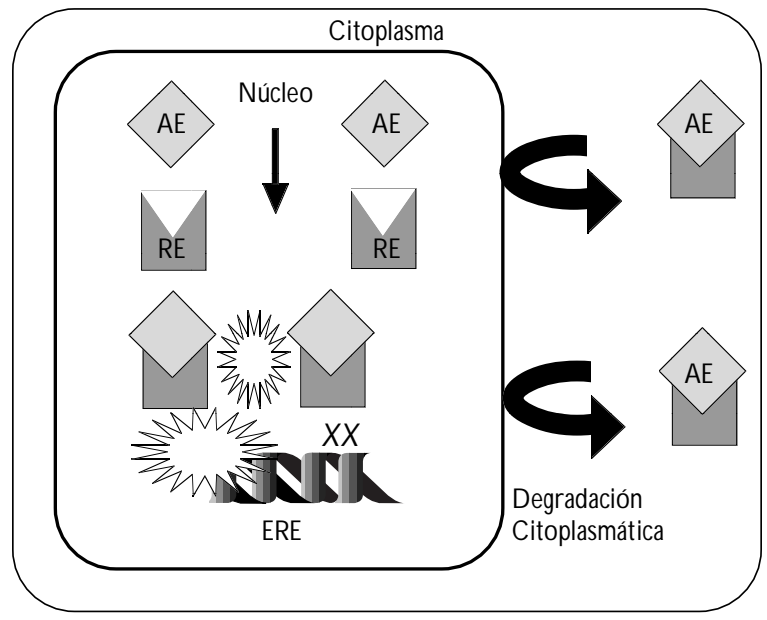

Figura 4. Estructura química (A) y mecanismo de ACCión de los antiestrógenos tipo II (B). RE: RECEPTOR DE ESTRÓGENOS. ERE: ELEMENTO DE RESPUESTA A ESTRÓGENOS. AE: ANTIESTRÓgeNOS 
censo significativo en la expresión del receptor de progesterona (RPg) y del RE en el tejido mamario, sin observarse alteraciones en los niveles circulantes de LH y FSH. ${ }^{73}$ Por lo anterior, se ha pensado que este compuesto podría ser útil como terapia del cáncer de mama avanzado, o en casos de enfermedad avanzada que haya desarrollado resistencia al tratamiento con Tamoxifén. ${ }^{75}$

\section{Conclusiones}

El cáncer de mama es una enfermedad cuya incidencia se ha incrementado en forma importante en México y el mundo. Su etiología es multifactorial y existen muchas evidencias de que la exposición crónica a niveles altos de estrógenos es un factor de riesgo muy importante para el desarrollo de esta patología. Además de este esteroide, se ha encontrado una correlación alta entre las concentraciones séricas de testosterona y el riesgo de desarrollar este tipo de cáncer en mujeres posmenopáusicas. ${ }^{76,77}$ Por un lado, se ha visto que en monos Rhesus la testosterona inhibe la proliferación de las células epiteliales de la mama inducida por el $\mathrm{E}_{2}$ así como la expresión del $\mathrm{RE}^{78}$ ejerciendo un papel protector para el desarrollo del cáncer. Este mismo efecto se observa cuando se administran simultáneamente estradiol y Tamoxifén en estos animales, lo cual sugiere que este fármaco ejerce un efecto similar a los andrógenos. Por lo anterior se piensa que la presencia de niveles circulantes bajos de testosterona podrían estar favoreciendo tanto la proliferación inducida por estrógenos de estas células, así como el incremento en el número de RE, con lo cual se estaría incrementando el riesgo de desarrollar cáncer mamario.

Por otro lado, y como se pudo constatar gracias a este documento, la terapia adyuvante con antiestrógenos ha revolucionado las estrategias de tratamiento para las pacientes de tumores malignos de mama que expresan el RE, generando así importantes expectativas en las estrategias de prevención de cáncer de mama en mujeres con elevado riesgo. Además de que se han empezado a utilizar en el tratamiento de enfermedades diferentes al cáncer y en los síntomas asociados a la menopausia. Seguramente el continuo avance en la investigación en este campo producirá los fármacos adecuados que procuren una mejor calidad de vida, tanto para las pacientes con cáncer de mama, como para las portadoras de otras patologías dependientes de estrógenos.

Por último, es importante considerar que la definición formal del término "antagonismo específico", hace referencia a la competencia entre un compuesto y su antagonista por un sitio particular de acción por el cual ambos tienen afinidad. ${ }^{79}$ Sin embargo, hoy, y sobre la base de los modelos propuestos para los mecanismos de acción de los agentes antiestrogénicos, los términos de agónico y antagónico deben ser utilizados considerando que algunas modificaciones menores en las proteínas receptoras, o dentro del microambiente celular, pueden cambiar un efecto agonista en antagonista, y viceversa. Por lo anterior se debe considerar que cada una de estas acciones por separado, o un comportamiento mixto, es el resultado de la expresión de un sistema complejo que incluye ligando, receptor, DNA y contexto celular, y por lo tanto no es una cualidad absoluta del ligando.

\section{Referencias}

1. Henderson B, Ross R, Bernstein L. Estrogens as a cause of human cancer:The Richard and Linda Rosenthal Foundation award lecture. $C$ ancer Res 1988; 48:246-253.

2. Hankinson S, Stampfer MJ. Estrogens and breast cancer. Salud Publica Mex 1997; 39:370-378.

3. Baynes K, Compton J. Selective estrogen receptor modulators: A new paradigm for HRT. C urr O p O bstet Gynecol 1998; 10:189-192.

4. Sadovsky Y,Adler $S$. Selective modulation of estrogen receptor action. (Editorial) J C lin Endocrinol Metab 1998; 83: 3-5.

5. Spencer C, Morris E, Rymer J. Selective estrogen receptor modulators:W o men's panacea for next millennium.Am J O bstet Gynecol 1999; 180:763-770.

6. Sar M, ParikhY. Immunohistochemical localization of estrogen receptor in rat brain, pituitary and uterus with monoclonal antibodies. J Steroid Biochem 1986; 24: 497-503.

7. Friend K,Ang L, Shupnik M. Estrogen regulates the expression of several different estrogen receptor $\mathrm{mRNA}$ isoforms in rat pituitary. Proc $\mathrm{N}$ atl Acad Sci USA 1995; 92:4367-4371.

8. Strauss J, Gurpide E.The endometrium: Regulation and dysfunction. En: Yen S, Jaffe R, ed. Reproductive endocrinology.Filadelfia (PA):W B Saunders, 1991: 309-353.

9. Going J,Anderson J, Batterby S, MacIntire A. Proliferation and secretory activity in human breast during natural and artificial menstrual cycles.Am J Pathol 1988; 130:193-198.

10. Clark J, Mani S.Actions of ovarian steroid hormones. En: Knobil E, N eill J,ed.The physiology of reproduction. 2da edición. N uevaYork:Raven Press, 1994;1:1011-1059.

11. Lachelin GC. The hypotalamus and pituitary gland. En: Introduction to clinical reproductive endocrinology. Londres: Butterwoth-Heinemann, 1991:1-35.

12. C iocca D ,Vargas-Roig L. Estrogen receptors in non-target tissues: Biological and clinical implications. Endocrine Rev 1995; 16:35-62.

13. Barrón A, Bermejo L, C astro I. El receptor de estrógenos y la glándula mamaria. Rev Invest C lin 1997; 49:515-528.

14. Greene G, Gilna P,W aterfield M, Baker A, H art Y, Shine J. Sequence and expression of human estrogen receptor complementary DNA. Science 1986; 231:1150-1154.

15. Mosselman S, Polman J, D ijkema R. ER $\beta$ : Identification and characterization of a novel human estrogen receptor. FEBS Lett 1996; 392:49-53.

16. Enmark E, Pello-Huikko M, Grandien K, Lagercrantz J, Fried G, $\mathrm{N}$ ordenskjold $\mathrm{M}$ et al. Human estrogen receptor $\mathrm{b}$ gene structure, chro- 
mosomal localization and expression pattern. J Clin Endocrinol Metab 1997; 82:4258-4265.

17. $O$ gawa $\mathrm{S}$, Inoue $\mathrm{S}, \mathrm{W}$ atanabe $\mathrm{T}$, Hiroi $\mathrm{H}, \mathrm{O}$ rimoto $\mathrm{A}$, Hosoi T et al. The complete primary structure of human estrogen receptor $b$ and his heterodimerization with ERa in vivo and in vitro. Biochem Byo phis Res Commun 1998; 243:122-126.

18. Moore J, Mckee D, Slentz-Kesler K, Moore L, Jones S, Horne E et al $C$ loning and characterization of human estrogen receptor $\beta$ isoformas. Biochem Byophis Res Commun 1998; 247:75-78.

19. G ustafsson JA.An update on estro gen receptors. Semin Perinatol 2000; 24:66-69.

20. Menasce P,W hite R, Harrisson J, Boyle M. Localization of the estrogen receptor locus (ESR) to chromosome $6 q 25.1$ by FISH and a simple postFISH technique. Genomics 1993; 17:263-265.

21. Enmark E, G ustafsson JA. 0 estrogen receptors- An overview.J Intern Med 1999; 246:133-138.

22. Petersson K, Grandien K, Kuiper G, Gustafsson JA. Mouse estrogen receptor $b$ forms estrogen response element-binding heterodimers with estrogen receptor a. Mol Endocrinol 1997; 11:1486-1496.

23. Hall JL, MCD onnell P. The estrogen receptor $b$ isoform (ERb) of the human estrogen receptor modulates ERa transcriptional activity and is a key regulator of the cellular response to estrogens and antiestrogens. Endocrinology 1999; 140:5566-5578.

24. Parker M, Arbukle N, D auvois $P, D$ anielian $P, W$ hite R. Structure and function of the estrogen receptor. Ann N Y Acad Sci 1993; 684:119-126.

25. Parker M. Structure and function of estrogen receptors.Vitam Horm, $1995 ; 51: 267-287$

26. Iwase H, O moto Y, Iwata H, Hra Y, Ando Y, Kobayash S. Genetic and epigenetic alterations of the estrogen receptor gene and hormone independence in human breast cancer. 0 ncology 1998; 55 Suppl 1:11-16.

27. Jordan C, Collins M, Rowsby L, Prestwich G. A monohydroxylated metabolite of tamoxifen with potent anti-oestrogenic activity.J Endocrinol 1977; 75:305-316.

28. Berry $M$, Metzger D,Chambon P. Role of the two activating domains of the oestrogen receptor in the cell-type and promoter-context dependent agonistic activity of the anti-oestrogen 4-hydroxytamoxifen. EMBO J 1990; 9:2811-2818

29. Katzenellenbogen B, Montano M, Le Goff P, Schodin D, Lee Kraus W, Bhardwaj B et al. Antiestrogens: Mechanism and actions in target cells. J Steroid Biochem Mol Biol 1995; 56:387-393.

30. McInerney El, Katzenellenbogen B. Different regions in activation function-1 of the human estrogen receptor required for antiestrogen-and estradiol-dependent transcription activation.J Biol C hem 1996; 271:2417224178.

31. N orris JD, Fan D, Kerner SA, MCD onnell DP. Identification of a third autonomous activation domain within the human estrogen receptor. Mol Endocrinol 1997; 11:747-754

32. Hedden A, Muller W, Jensen E.A new interpretation of estrogen action. Ann N Y Acad Sci 1995; 761:109-120.

33. G ee A, C arlson K, Martini P, Katzenellenbogen B, Katzenellenbogen J. Coactivator peptides have a differential stabilising effect on the binding of estrogens and antiestrogens with the estrogen receptor. Mol Endocrinol 1999; 13:1912-1923.

34. Montano M, Ekena K, D elage R, C hang W, Martini P, Karzenellenbogen B. An estrogen receptor-selective corregulator that potentiates the effectiveness of antiestrogens and represses the activity of estrogens. Proc $N$ atl Acad Sci USA 1999; 96:6947-6952.

35.Takimoto G, Graham J,Jackson T,Tung L, Powell R, Horwitz L.Tamoxifen resistant breast cancer: Corregulators determine the direction of transcription by antagonist-occupied steroid receptors.J Steroid Biochem Mol Biol 1999; 69:45-50.

36. Barkem T, C arlsson BO, N ilsson Y, Enmark E, G ustafsson J, N ilsson S. Differential response of estrogen receptor $b$ to partial estrogen agonists/ antagonists. Mol Pharmacol 1999; 54:105-112
37. Peach K, Webb P, Kuiper G, N ilsson S, G ustafsson J, Kushner $P$, et al. $D$ ifferential ligand activation of estrogen receptors $a$ and $b$ at AP 1sites. Science 1997; 277:1508-1510.

38. MacG regor J, Jordan C. Basic guides to the mechanism of antiestrogen action. Pharmacol Rev 1998; 50:151-195.

39. Early Breast $\mathrm{C}$ ancer Trialist Collaborative Group (EBCTCG). Systematic Treatment of early breast cancer by hormonal, cytotoxic, or immune therapy: 133 randomized trials involving 31000 recurrences and 24000 deaths among 75000 women. Lancet 1992; 339:1-15.

40. Early Breast Cancer Trialist Co llabo rative Group (EBC TCG ).Tamoxifen for early breast cancer: An overview of the randomized trials. Lancet 1998. 351:1451-1467.

41. Bilimoria M,Assiskis J, Jordan C. Should adjuvant tamoxifen treatment be stopped at 5 years? Cancer J Sci Am 1996; 2:140-150

42. Kangas L. Review of pharmacological properties of Toremifene. J Steroid Biochem 1990; 36:191-195.

43. Hard G, latropoulus M, Jorda K. Major differences in the hepatocarcinogenicity and DNA adduct forming ability between toremifene and tamoxifen in Female Crl: CD (BR) rats. Cancer Res 1993; 53:4534-4541. 44. Hirsimarski $P$, Hirsimarski $Y, N$ ieminen $L$, Paine $B$. Tamoxifen induces hepatocellular carcinoma in rat liver: A 1-year study with two antiestrogens. Arch Toxicol 1993;67:49-59.

45. Tomas E, Kauppila A, Blanco G. Comparison between the effects of tamoxifen and toremifen on the uterus in postmenopausal breast cancer patients. Ginecol O ncol 1995; 59:261-266.

46. McC ague R, Parr B, Haynes P. Metabolism of the 4-yodo derivative of tamoxifen by isolated rat hepatocytes: $D$ emonstration that the iodine atom reduces metabolic conversion and identification of four metabolites. Biochem Pharmacol 1990; 40:1355-1361.

47. Chandler S, McC ague R, Lugmani Y. Pyrrolidino-4-iodotamoxifen and 4-iodotamoxifen, new analogues of the antiestrogen tamoxifen for the treatment of breast cancer. C ancer Res 1991; 51:5851-5858.

48. Hasman M, Rattel B, Loser R. Preclinical data for Droloxifene. C ancer Lett 1994; 84:101-106

49. Rausching W, Pritchard K. D roloxifene, a new antiestrogen: Its role in metastatic breast cancer. Breast C ancer Res Treat 1994; 31:83-94.

50. Gradishar W, Jordan C. C linical potential of new antiestrogens. J C lin Oncol 1997; 15:840-852.

51. Black L, Goode R. Uterine bioassays of tamoxifen, trioxifen and a new estrogen antagonist (LY 117018) in rats and mice. Life Sci 1980; 26:1453-1458. 52. Black L, Goode R. Evidence for biological action of the antiestrogens LY 117018 and tamoxifen by different mechanisms. Endocrinology 1981; 109:987-989.

53. Black $L$, Jones $C$, Falcone J. Antagonism of estrogen action with a new benzothio phene-derived antiestrogen. Life Sci 1983; 32:1031-1036.

54. Jordan C, G osden B. Inhibition of the uterotrophic activity of estrogens and antiestrogens by the short acting antiestrogens LY 117018 . Endocrinology 1983; 113:463-468.

55. Jordan C, Phelps E, Lindgren J. Effects of antiestrogens on bone in castrated and in intact female rats. Breast Cancer Res Treat 1987; 10:31-35.

56. Sato $M$, , Bryant $H$, Iverson P, Smietana F, Bemis $K$, Higgs $R$ et al. Advantages of raloxifen over alendronato or estrogen on non-reproductive tissues in the-long term dosing of ovariectomized rats. J Pharmacol Exp Ther 1996; 279:298-305.

57. Evans $G$, Bryant $H$, Magee $D$, Turner R. Raloxifene inhibits bone turnover and prevents further cancerous bone loss in adult ovariectomized rats with stablisshed osteopenia. Endocrinology 1996; 134:2283-2288.

58. Frolick C, Bryant H, Black E, Magee D, Chandrasekar S.Time-dependent changes in biochemical bone markers and serum cholesterol in ovariecto mized rats: Effects of raloxifene, tamoxifen, estrogen and alendronate. Bone 1996; 18:621-627.

59. D raper M, Flowers D, Hester W, N eild J, Harper K, Arnaud C. A controlled trial of raloxifene: Impact on bone turnover and serum lipid in healthy postmenopausal women.J Bone Miner Res 1996; 11:835-842. 
60. Scholl M, Huff K, Lippman M. Antiestrogenic effects of LY 117018 in MCF-7 cells. Endocrinology 1983; 113:611-617.

61.G ottardis M,Jordan C.The antitumor action of keoxifene and tamoxifen in the $\mathrm{N}$-nitrosomethyurea-induced rat mammary carcinoma model. Cancer Res 1987; 47:4020-4024.

62. Anzano M, Peer C, Smith J, Mullen L, Shrader M, Logsdon D et al. Chemoprevention of mammary carcinogenesis in the rat: Combined use of raloxifen and 9-cis-retinoic acid. J $N$ atl $C$ ancer Inst 1996; 88:123-125.

63. Weryha G, Pasacal-Vigneron V, Klein M, Leclere J. Selective estrogen receptor modulators. Curr $0 \mathrm{p}$ Rheumatol 1999; 11:301-306.

64. Buzdar V, Marcus C, Holmes F. Phase II evaluation of LY 156758 in metastatic breast cancer. 0 ncology 1988; 45:344-345.

65. Fawell S,W hite R, Hoare S, Sideham M, Page M, Parker M. Inhibition of estrogen receptor-DNA binding by the pure antiestrogen ICI 164384 appears to be mediated by impaired receptor dimerization. Proc $\mathrm{N}$ atl Acad Sci USA 1990; 87:6883-6887.

66. Gibson M, Nemmas L, Beckman W. The mechanism of ICI 164384 antiestrogenicity involves rapid loss of estrogen receptor in uterine tissue. Endocrinology 1991; 129:2000-2010.

67. Davo is S,W hite R, Parker M.The antiestrogen ICI 182,780 disrupts estrogen receptor nucleocytoplasming shuttling.J Cell Sci 1993; 106:1377-1388.

68. G ottardis M, Jiang S, Jeng M, Jordan C. Inhibition of tamoxifen stimulated growth of MCF-7 tumour variants in athymic mice by novel steroidal antiestrogens. C ancer Res 1989; 49:4090-4093.

69. W akeling A, Dukes M, Bowler J. A potent specific pure antiestrogen with clinical potential. C ancer Res 1991; 51:3867-3873.

70. Gottardis M, Ricchio M, Satyaswaroop P, Jordan C. Effect of steroidal and non-steoidal antiestrogens on the growth of a tamoxifen-stimulated human endometrial carcinoma (EnC a101) in athymic mice. Cancer Res 1990; 50:3189-3192.

71. D ukes $M, W$ aterton J,W akeling A. Antiuterotrophic effect of the pure antiestrogen ICI 182,780 in adult female monkeys (Macaca nemestrina): Q uantitative magnetic resonance imaging.J Endocrinol 1993; 138:203-210. 72. DeFriend $D$, Howell $A, N$ icholson R. Investigation of a pure new antiestrogen (ICI 182,780) in women with primary breast cancer. Cancer Res 1994; 54:408-414.

73. W akeling A, Bowler D. N ovel antiestrogens without partial agonist activity.J Steroid Biochem 1988; 31:645-653.

74. 0 sborne C, C oronado-Heinsohn E, Hilsenbeck S. Comparison of the effects of a pure steroidal antiestrogen with those of tamoxifen in a model of human cancer.J N atl C ancer Inst 1995; 87:746-750.

75. Howell, 0 sborne CK, Morris CH,W akelingA . ICI 182780 (Faxlodex ${ }^{\top M}$ ). Development of a novel, "pure" antiestrogen. Cancer 2000;89:817-825

76. Dorgan JF, Longcope C, Stephenson HE Jr, Falk RT, Miller R, Franz C et al. Relation of prediagnostic serum estrogen and androgen levels to breast cancer risk. C ancer Epidemiol Biomarker Prevent 1996;5:533-539.

77. Berrino F, Muti P, Michelli A, Bolelli G, Krogh V, Sciajno R et al. Serum sex hormones levels after menopause and subsequent breast cancer. J $N$ atl $C$ ancer Inst 1996;88:291-296.

78. Zhou J, N G Siu, Adesanya-Famuiya O, Anderson K, Bondy CA. Tetosterone inhibits estrogen-induced mammary epithelial proliferation and suppresses estrogen receptor expresion. FASEB J 2000;14:1725-1730. 79. A pplezweig N. Steroid drugs. N uevaYork: McG raw Hill Book Company 1962: 131-132. 